\title{
Editorial
}

\section{Shape and Topology Optimization for Complicated Engineering Structures}

\author{
Ji-Hong Zhu, ${ }^{1}$ Pierre Beckers, ${ }^{2}$ Marc Dahan, ${ }^{3}$ Jun Yan, ${ }^{4}$ and Chao Jiang ${ }^{5}$ \\ ${ }^{1}$ Engineering Simulation and Aerospace Computing, Northwestern Polytechnical University, Xi'an 710072, China \\ ${ }^{2}$ LTAS-Infographie, University of Liege, 4000 Liege, Belgium \\ ${ }^{3}$ Department of Applied Mechanics, The University of Franche-Comté, 25000 Besançon, France \\ ${ }^{4}$ State Key Laboratory of Structural Analysis for Industrial Equipment, Department of Engineering Mechanics, \\ Dalian University of Technology, Dalian 116024, China \\ ${ }^{5}$ State Key Laboratory of Advanced Design and Manufacturing for Vehicle Body, College of Mechanical and Automotive Engineering, \\ Hunan University, Changsha 410082, China
}

Correspondence should be addressed to Ji-Hong Zhu; jh.zhu@nwpu.edu.cn

Received 17 May 2015; Accepted 31 May 2015

Copyright (C) 2015 Ji-Hong Zhu et al. This is an open access article distributed under the Creative Commons Attribution License, which permits unrestricted use, distribution, and reproduction in any medium, provided the original work is properly cited.

Advanced optimization methods have been addressed as the most promising techniques for least-weight and performance design of engineering structures (e.g., Martinez et al. [1], Vitali et al. [2], Hansen and Horst [3], Grihon et al. [4], and Chintapalli et al. [5]). During the last 30 years, many theoretical achievements have been obtained both mechanically and mathematically, which was addressed in the survey papers such as Guo and Cheng [6], Sigmund and Maute [7], and Deaton and Grandhi [8]. Nowadays, the great challenge lies in solving more complicated engineering design problems with multidisciplinary objectives or complex structural systems (see Zhu et al. [9]).

Another important issue in structural optimization is the reliability-based optimization, where uncertainties in geometric dimensions, material properties, loads, boundary conditions, and so forth existing in practical engineering problems are considered. Different effective methods such as the probability methods and the interval methods have been proposed till now (see Jiang and Han [10]).

Focusing on the above mentioned topics, 8 research papers have been published in this special issue. The contents are summarized as follows.

The paper titled "Structural Response Analysis under Dependent Variables Based on Probability Boxes" by Z. Xiao and G. Yang proposed a sampling-based method to calculate uncertainty structural responses. They used a sampling strategy to consider the random intervals from dependent probability boxes. Different structural interval response problems were then solved with the metamodel-based optimization method.

In the paper titled "Reliability-Based Topology Optimization Using Stochastic Response Surface Method with Sparse Grid Design" by Q. Zhao et al., performance measure approach (PMA) and the sequential optimization and reliability assessment (SORA) were used to deal with the reliability-based topology optimization problems. Stochastic response surface method (SRSM) and the sparse grid design (SGD) are used to enhance the computational efficiencies.

The paper titled "Reliability Analysis of High Rockfill Dam Stability" by P. Yi et al. introduced the slope stability analysis and reliability analysis which were combined in a program to deal with the stability reliability analysis of concrete faced rockfill dams. The safety factor of the critical slip surface was calculated using the limit equilibrium method.

The paper titled "Improved Genetic Algorithm with Two-Level Approximation for Truss Optimization by Using Discrete Shape Variables" by S. Chen et al. presented a simultaneous optimization procedure with size, shape, and topology variables. In the two-level approximation strategy, 
genetic algorithm was well applied to deal with mixed and even discretized variables.

The paper titled "Improved Reliability-Based Optimization with Support Vector Machines and Its Application in Aircraft Wing Design" by Y. Wang et al. proposed a new reliability-based design optimization method based on Support Vector Machines (SVM) and the Most Probable Point (MPP). Importance Sampling (IS) is used to calculate the failure probability based on the surrogate model. The improved method was then proved to be more accurate and efficient in numerical examples.

The paper titled "Improved Genetic Algorithm with Two-Level Approximation Method for Laminate Stacking Sequence Optimization by Considering Engineering Requirements" by $\mathrm{H}$. An et al. used genetic algorithm to optimize the stacking sequences of laminated composites. With a new two-level strategy, random initial designs were provided to present better optimization design. The efficiency and feasibility of these improvements were verified with illustrative and industrial examples.

The paper titled "Optimization of the Turbulence Model on Numerical Simulations of Flow Field within a Hydrocyclone" by Y. Xu et al. used Reynolds Stress Model and Large Eddy Simulation to, respectively, perform numerical simulation for the flow field of a hydrocyclone. Compared with the Laser Doppler Velocimeter test results, the results obtained from Large Eddy Simulation were proved to be more accurate and reliable.

In the paper titled "Multidisciplinary Inverse Reliability Analysis Based on Collaborative Optimization with Combination of Linear Approximations" by X.-J. Meng et al., the multidisciplinary reliability assessment problem was transformed into a most probable failure point problem which will be solved later with combination of linear approximations. The proposed method is highly efficient and very convenient in treating nonnormal distribution variables.

\section{Acknowledgments}

We would like to express our faithful gratitude to all the contributors to this special issue for their support and to all the reviewers for their constructive and timely comments.

\author{
Ji-Hong Zhu \\ Pierre Beckers \\ Marc Dahan \\ Jun Yan \\ Chao Jiang
}

[4] S. Grihon, L. Krog, and D. Bassir, "Numerical Optimization applied to structure sizing at AIRBUS: a multi-step process," International Journal for Simulation and Multidisciplinary Design Optimization, vol. 3, no. 4, pp. 432-442, 2009.

[5] S. Chintapalli, M. S. A. Elsayed, R. Sedaghati, and M. Abdo, "The development of a preliminary structural design optimization method of an aircraft wing-box skin-stringer panels," Aerospace Science and Technology, vol. 14, no. 3, pp. 188-198, 2010.

[6] X. Guo and G.-D. Cheng, "Recent development in structural design and optimization," Acta Mechanica Sinica, vol. 26, no. 6, pp. 807-823, 2010.

[7] O. Sigmund and K. Maute, "Topology optimization approaches," Structural and Multidisciplinary Optimization, vol. 48, no. 6, pp. 1031-1055, 2013.

[8] J. D. Deaton and R. V. Grandhi, "A survey of structural and multidisciplinary continuum topology optimization: post 2000," Structural and Multidisciplinary Optimization, vol. 49, no. 1, pp. 1-38, 2014.

[9] J. H. Zhu, W. H. Zhang, and L. Xia, “Topology optimization in aircraft and aerospace structures design," Archives of Computational Methods in Engineering, 2015.

[10] C. Jiang and X. Han, "A new uncertain optimization method based on intervals and an approximation management model," Computer Modeling in Engineering and Sciences, vol. 22, no. 2, pp. 97-118, 2007.

\section{References}

[1] M. P. Martinez, A. Messac, and M. Rais-Rohani, "Manufacturability-based optimization of aircraft structures using physical programming," AIAA journal, vol. 39, no. 3, pp. 517-525, 2001.

[2] R. Vitali, O. Park, R. T. Haftka, B. V. Sankar, and C. A. Rose, "Structural optimization of a hat-stiffened panel using response surfaces," Journal of Aircraft, vol. 39, no. 1, pp. 158-166, 2002.

[3] L. U. Hansen and P. Horst, "Multilevel optimization in aircraft structural design evaluation," Computers \& Structures, vol. 86, no. 1-2, pp. 104-118, 2008. 


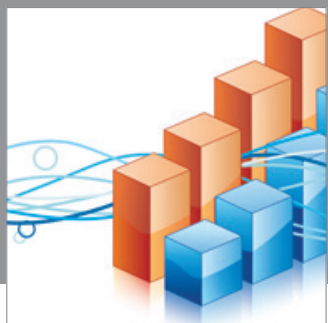

Advances in

Operations Research

mansans

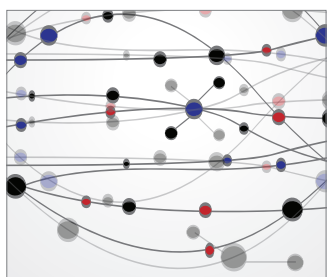

The Scientific World Journal
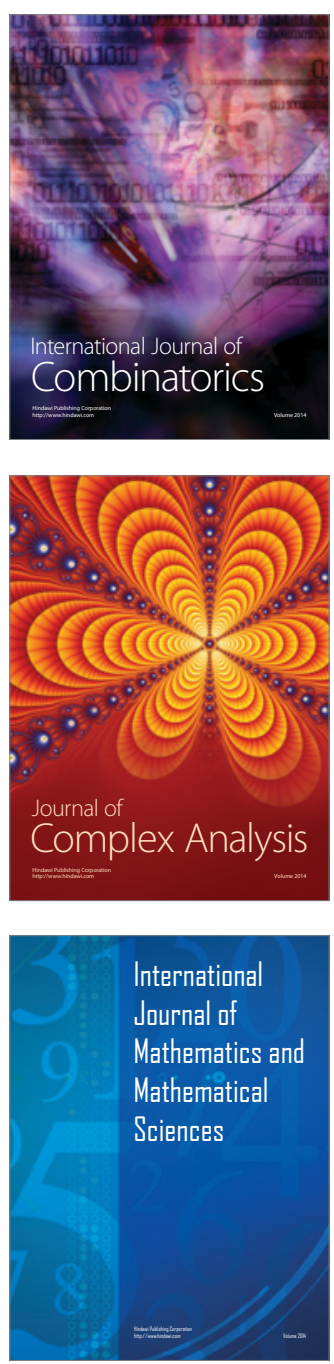
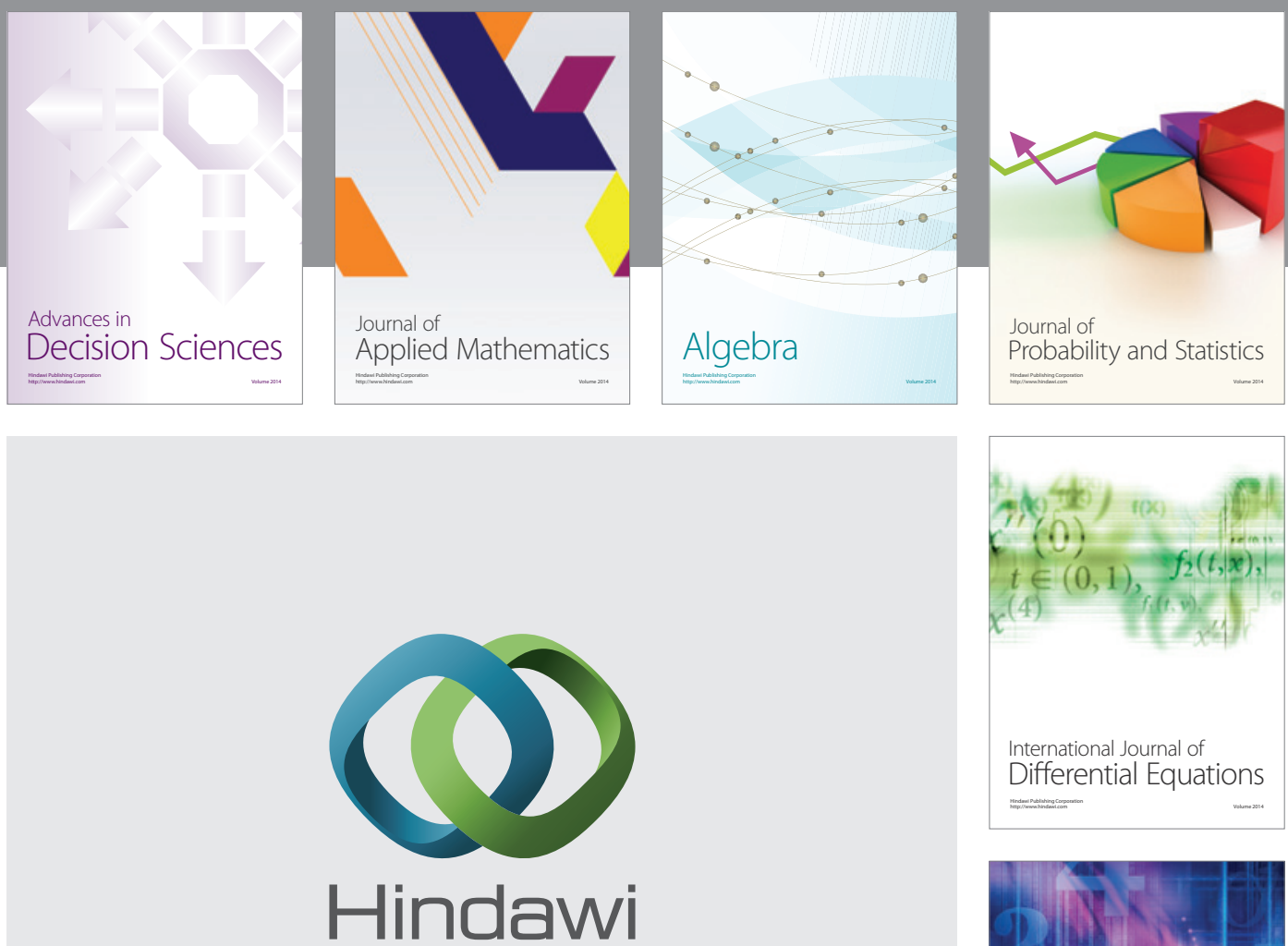

Submit your manuscripts at http://www.hindawi.com
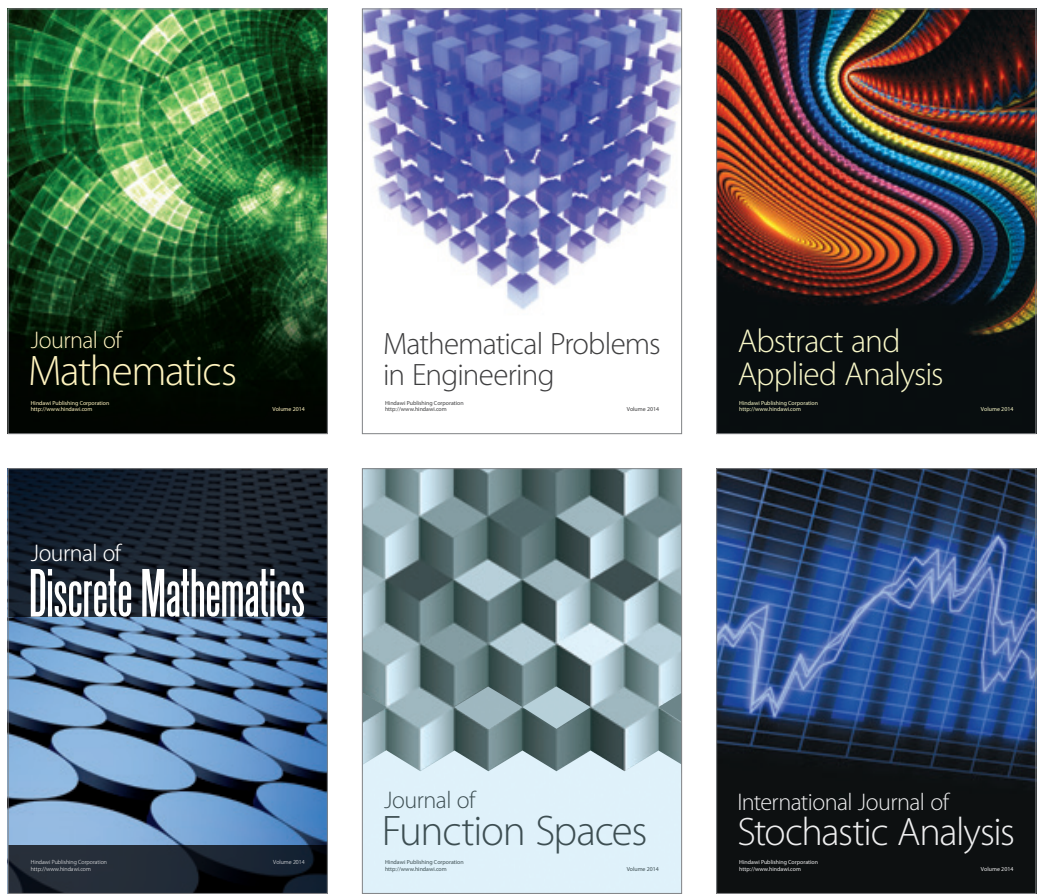

Journal of

Function Spaces

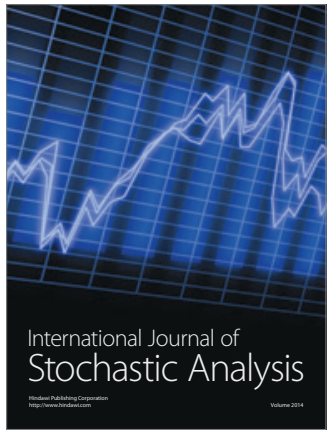

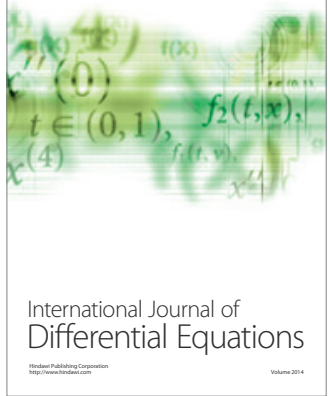
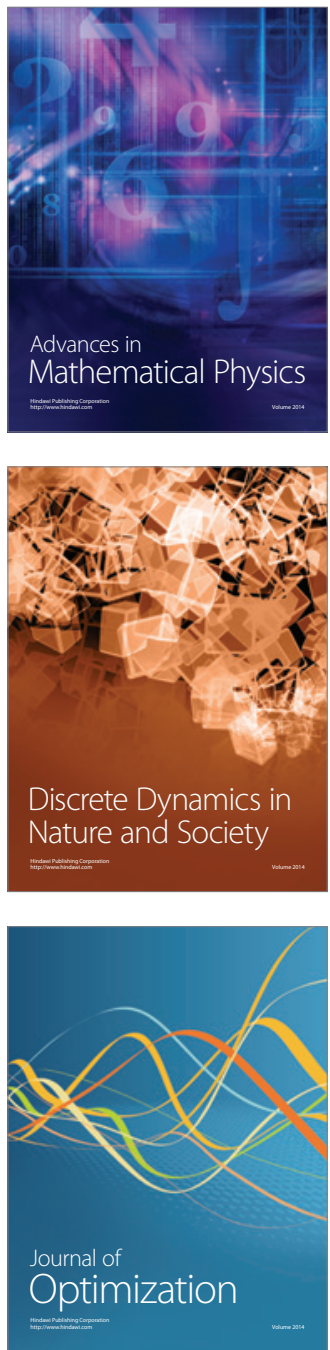